
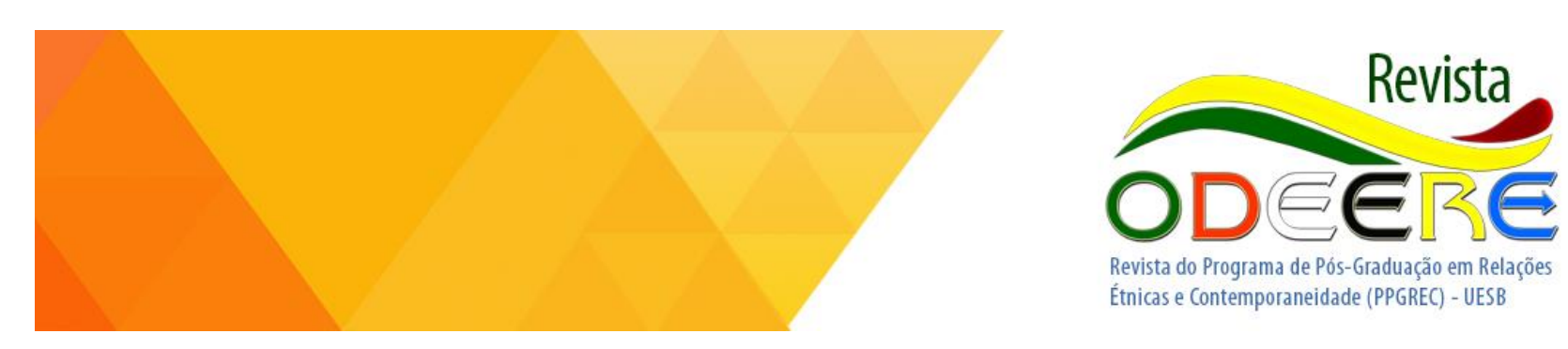

\title{
A importância das mulheres do candomblé no desenvolvimento de Cachoeira, BA.
}

\author{
Sandro dos Santos Correia \\ Universidade do Estado da Bahia (UNEB) \\ sscorreia@uneb.br
}

Resumo: $O$ presente trabalho tem como objetivo refletir sobre o papel das mulheres no fortalecimento do candomblé por meio de suas variadas atuações desde a sacerdotal, a ritualística, a comercial, até a política. A metodologia utilizada está calcada no trabalho de campo e investigação participante em alguns terreiros e diálogo com lideranças religiosas no território de Cachoeira, no estado da Bahia; concentrando a análise na função destas mulheres na organização de festas públicas como a da Boa Morte e a de lemanjá e outras, como a da Pechincha e a feijoada de Mãe Preta; abrangendo toda a atuação feminina que vai desde o enfrentamento público e a própria construção logística e financeira destas intervenções, que contribuem para uma imagem positiva da cultura de matriz africana praticada no interior de templos religiosos, como até o reconhecimento destas para o processo de inclusão, na atualidade, de toda uma população marcada pela Escravidão Oficial, que historicamente foi excluída do desenvolvimento por práticas de preconceito, racismo e discriminação.

Palavras-Chave: Mulheres, Candomblé, Desenvolvimento, Território de Cachoeira, Festas Públicas. 
The importance of candomblé women in the development of Cachoeira, BA.

Abstract: The present work had as objective
to reflect on the role of women in the
strengthening of candomble through its
varied activities from priestly, ritualistic,
commercial, to political, having a
methodology based on field work and
participant research in some terreiros And
dialogue with religious leaders on the
territory of Cachoeira in the state of Bahia;
Concentrating their analysis on the role of
these women in the organization of public
parties such as Boa Morte and lemanjá, and
others such as Pechincha and Feijoada de
Mãe Preta, but also of all women's activities ranging from public confrontation and Logistical and financial construction of these interventions that contribute to a positive image of the African matrix culture practiced within religious temples and how these actions are important for the process of inclusion of an entire population marked by Official Slavery and that was excluded from development by Practices of prejudice, racism and discrimination.

Keywords: Women, Candomblé, Development, Territory of Cachoeira, Public Holidays.

Este ensaio teórico contém reflexões que emergiram no Doutorado em Planejamento Territorial e Desenvolvimento Social da UCSAL (Universidade Católica de Salvador) com o Estudo em andamento intitulado "O território de Cachoeira-BA: o potencial do patrimônio cultural e as possibilidades para o desenvolvimento local" $\underline{\underline{1}}$ na linha de pesquisa: territorialidade, desenvolvimento social e meio ambiente.

O objetivo é demonstrar a importância das mulheres ligadas ao candomblé para o desenvolvimento da cidade de Cachoeira, no estado da Bahia, através das atividades que organizam diretamente ou que tenham alguma relação com a religião, com repercussão na dinâmica local por atrair pessoas de outras cidades.

\footnotetext{
${ }^{1}$ Esta Pesquisa tem apoio da FAPESB (Fundação de Apoio a Pesquisa do Estado da Bahia) com uma bolsa de estudos a nível de Doutorado;
} 
Tais atividades, normalmente, são organizadas pelas lideranças como sacerdotisas ou como Ebâmis $^{2}$ ou pelas demais adeptas que desempenham outras funções, como as atividades realizadas no interior das comunidades-terreiro e que também participam das festas coletivas da Irmandade da Boa Morte e de lemanjá, ambas são intimamente ligadas com a matriz africana em seus aspectos religiosos ou culturais, além da festa da Pechincha e a Feijoada de Mãe Preta.

A reflexão sobre o papel das mulheres objetiva perceber a importância, não somente do seu papel enquanto liderança, mas enquanto agente de resistência e desconstrução de uma ordem machista calcada em valores militares e operacionalizado pela estrutura da violência, seja ela institucionalizada pelo aspecto psicológico, de gênero, racial, cultural e outros.

Estas ações foram produzindo um impacto positivo da participação das mulheres da vida em família e em sociedade, dando-Ihes uma significativa importância e uma capacitação na sua qualificação política de tomar decisões e dirigir projetos e vencer desafios postos.

O mesmo se aplica a muitas outras áreas da ação econômica, política e social, variando do crédito rural e atividades econômicas, de um lado, à discussão e debates sociais, de outro. O grande alcance da condição de agente das mulheres é uma das áreas mais negligenciadas nos estudos sobre o desenvolvimento e requer correção urgente. Pode-se dizer que nada atualmente é tão importante na economia política do desenvolvimento quanto um reconhecimento adequado da participação e da liderança política, econômica e social das mulheres. Esse é, de fato, um aspecto crucial do "desenvolvimento como liberdade"

Para avançar na importância não só reprodutiva e de criação das novas gerações é urgente o investimento em pesquisas que observem o modo que algumas comunidades ou organizações que tem a frente mulheres resolvem os problemas e vencem os desafios nos dias atuais.

A reflexão sobre o papel das mulheres do candomblé objetiva perceber a importância destas no território, vendo este desenvolvimento como um processo de fortalecimento das liberdades civis e políticas.

Não somente do seu papel enquanto liderança, mas enquanto agente de resistência e desconstrução de uma ordem neoliberal e machista calcada em valores militares e

\footnotetext{
${ }^{2}$ Ebâmi. Filha de Santo que tem sete anos ou mais de iniciação. Do iorubá ègbón mi, “meu mais velho". (LOPES, 2004, p. 248).

${ }^{3}$ (SEN, 2015, p. 263).
} 
operacionalizado pela estrutura da violência, seja ela institucionalizada pelo aspecto psicológico, de gênero, racial, cultural e outros.

\section{As mulheres, o candomblé e o desenvolvimento}

Esta necessidade de conhecer experiências vividas por mulheres nasce uma afirmação que mesmo não conhecendo estas histórias de superação uma coisa pode-se ter certeza de que sem a participação feminina pouco êxito se terá na superação de obstáculos e a lenda intitulada "Oxum faz as mulheres estéreis em represália aos homens" exemplifica uma relação de que é preciso ter equipolência.

Para isto foi pensado em nossa primeira reflexão com uma lenda ligada ao orixá Oxum que irá revelar uma tentativa também no mundo das entidades religiosas de uma subalternização ao poder sagrado feminino, dizendo o seguinte:

Oxum faz as mulheres estéreis em represália aos homens Logo que o mundo foi criado, Todos os orixás vieram para a Terra

E começaram a tomar decisões e dividir encargos entre eles, Em conciliábulos nos quais somente os homens podiam participar.

Oxum não se conformava com essa situação. Ressentida pela exclusão, ela vingou-se dos orixás masculinos.

Condenou todas as mulheres à esterilidade,

De sorte que qualquer iniciativa masculina No sentido da fertilidade era fadada ao fracasso. Por isso, os homens foram consultar Olodumare.

Estavam muito alarmados e não sabiam o que fazer Sem filhos para criar nem herdeiros para quem deixar suas posses, Sem novos braços para criar novas riquezas e fazer as guerras E sem descendentes para não deixar morrer suas memórias. Olodumare soube, então, que Oxum fora excluída das reuniões.

Ele aconselhou os orixás a convidá-la, e às outras mulheres, Pois sem Oxum e seu poder sobre a fecundidade Nada poderia ir adiante. Os orixás seguiram os sábios conselhos de Olodumare E assim suas iniciativas voltaram a ter sucesso. As mulheres tornaram a gerar filhos E a vida na Terra prosperou ${ }^{4}$.

\footnotetext{
${ }^{4}$ (PRANDI, 2001, p. 345)
} 
A lenda nos coloca uma discussão muito importante e estruturante que irá atentar para as questões relacionadas a função da mulher no processo da demografia a de geração biológica dos novos seres humanos.

Função tão sagrada que no primeiro sinal de formação de uma vida vem a família para se formar a primeira unidade nuclear a célula da sociedade e logo após a comunidade em que irá criar várias outras organizações espaciais como municípios, cidades, estados, países e todo o nosso planeta.

O elemento feminino representado por Oxum por meio da condenação das mulheres pela esterilidade, por meio da decisão e a participação ser algo do homem excluindo a fêmea e qualquer tentativa masculina com relação a fertilidade estaria fadada ao insucesso.

As consequências advindas desta ausência de fertilidade estariam na ausência de novos seres, novos filhos, não havendo heranças e nem continuidade; não havendo novas pessoas não haveriam novos braços para criar novas riquezas, defender as riquezas e fronteiras e; a não exploração de novos recursos e a não criação de exércitos para as guerras por falta de novos soldados.

Pertence a Oxum $^{5}$, um orixá feminino, a essência da fertilidade, da procriação, do nascimento, da formação, da construção, claro que aos orixás femininos o dom da fertilidade estará sempre presente, mas Oxum foi escolhida por ser um orixá muito presente e cultuado no seio do candomblé com destaque de várias mães de santo que pertencem a Oxum, inclusive as saudosas Mãe Menininha do Gantois em Salvador e Mãe Baratinha do llê Kaió Alaketu Axé Oxum em Cachoeira.

Esta lenda possui uma relação com a realidade ao trazer a questão de gênero vivida na sociedade em que a relação de poder entre homem e mulher é estabelecida tendo como base a questão biológica e a verticaliza sendo que a fêmea sempre está abaixo do macho.

\footnotetext{
${ }^{5}$ Orixá iorubano das águas doces, da riqueza, da beleza e do amor. Segundo alguns relatos tradicionais, é divindade superior, tendo participado da Criação como provedora das fontes das águas doces. É o nome tutelar do rio Óshun, que nasce em Ekití, no Leste da Nigéria, e passa pela cidade de Oshogbo, onde se localiza seu primeiro santuário. Seus principais símbolos são seixos rolados e pequenos bastões que a distinguem das demais entidades. (LOPES, 2004, p. 505).
} 
Ao tempo em que a lenda apontando para a equipolência na relação entre o feminino e o masculino irá construir um processo de equilíbrio nas relações ao trazer o elemento da decisão para o campo político com os seus desdobramentos no processo da sociedade.

Chegando a compreensão de que ao momento em que a opinião de Oxum, representando este feminino, foi considerada e levada em consideração foi restabelecido então o equilíbrio e garantida as próximas gerações o direito de viver e ir se desenvolvendo por meio da renovação graças ao restabelecimento da fertilidade.

Dentro do candomblé este equilíbrio está no xirê ${ }^{6}$ ao estabelecer um círculo, uma roda, uma circunferência em que no sentido circular irá horizontalizar a relação de importância entre os orixás e relacionando ao processo de complementaridade colocado pela lenda de Oxum em que irá permitir que a liderança feminina no seio do candomblé ganhe força e evidência.

Em uma realidade de um país em desenvolvimento como o Brasil com um passado escravista e colonização portuguesa e europeia de exploração, o papel da mulher é ainda muito mais inferiorizado e subjugado a uma importância menor, sendo que as relações sociais, extremamente marcadas pelo machismo vão fazer da mulher um ser frágil e de constantes depreciações de ordem moral e social.

Em uma cidade como Cachoeira, do Recôncavo Baiano e Nordeste Brasileiro com uma menor inserção no contexto regional do desenvolvimento do Brasil por ser uma região com menor índice de industrialização e urbanização, marcada pelos baixos índices de escolaridade e cabendo o papel da reprodução dos latifúndios com destaque para a cana-de-açúcar e o fumo.

No candomblé7, religião criada no Brasil com sua institucionalização em torno de 1860 viveu forte perseguição policial, política e cultural por parte do Estado através de sua criminalização sendo que o Decreto Estadual $25095^{8}$ de 13 de janeiro de 1976 iniciou a

\footnotetext{
${ }^{6}$ Festa pública dos candomblés, na qual se executam os cânticos invocatórios dos orixás. Por extensão, o termo designa também o conjunto ordenado dos toques, cantigas e danças com os quais os orixás são invocados. (LOPES, 2004, p. 689).

${ }^{7}$ Candomblé. Nome genérico com que, no Brasil, se designam o culto aos orixás jeje-nagôs e algumas formas dele derivadas, manifestas em diversas "nações". Por extensão, celebração, festa dessa tradição, xirê; comunidade-terreiro onde se realizam essas festas. A modalidade original consiste em um sistema religioso autônomo e específico que ganhou forma e se desenvolveu no Brasil, a partir da Bahia, com base em diversas tradições religiosas de origem africana, notadamente da região do Golfo da Guiné. (LOPES, 2004, P. 162).

${ }^{8}$ DECRETO ESTADUAL (BA) № 25.095, DE 25 DE JANEIRO DE 1976
} 
desobrigação dos terreiros de candomblé de solicitarem licença a delegacia de jogos e costumes para a realização de suas atividades ritualísticas e religiosas.

O papel do candomblé parece ter sido este, de se constituir enquanto instituição capaz de salvaguardar a memória dos povos explorados, não só os africanos, mas principalmente, os afrobrasileiros e o papel da mulher neste processo foi fundamental em razão desta inferiorização civilizatória oficial por meio da criminalização.

Há grandes indícios que houve uma participação maior da mulher em sua construção em que o objetivo não se concentrava em transmitir a cultura do colonizador e sim em manter viva uma cultura que estava sendo destruída em razão de uma conjuntura política, econômica e cultural que inferiorizava o legado civilizatório de povos africanos escravizados no período da Escravidão.

A citação no emblemático livro de Ruth Landes (2002) enfatiza a importância do papel da mulher no candomblé da Bahia na cidade do Salvador com destaque para o terreiro do Gantois fundado por Mãe Menininha e atualmente dirigido por Mãe Creuza:

Eram mulheres do candomblé que canalizavam a vida das gentes na Bahia e assim foi um grande acontecimento quando se espalhou a notícia de que o Gantois ia realizar os ritos cruciais do axexê para limpar o templo dos sombrios miasmas trazidos pela morte de ogã Bibiano, um ano antes. 0

Define o sentido e alcance da previsão legal a que alude.

O Governador do Estado da Bahia, no uso de suas atribuições e considerando que, na expressão "sociedades afrobrasileiras para atos folclóricos", a que se refere a Tabela I, anexa a Lei no 3.097, de 29 de dezembro de 1972 se tem identificado para fins de registro e controle nela previstos, as entidades que exercitam o culto Afro-Brasileiro, como forma exterior da religião que professam;

Considerando que semelhante entendimento se não ajusta no sentido e alcance da lei, sendo antes antagônico ao princípio constitucional que assegura a liberdade do exercício do culto;

Considerando que é dever do poder público garantir aos integrantes da comunhão política que dirige, o livre exercício do culto de cada um, obstando quaisquer embargações que o dificultam ou impeçam;

Considerando afinal que, se assim lhe incumbe proceder para com todas as crenças e confissões religiosas, justo não seria que também não fizesse em relação às sociedades do culto Afro-Brasileiro, que idêntico modo têm a liberdade de regerem-se de acordo com a sua fé.

Decreta:

Art. 10 Não se incluem, na previsão do item 27 da tabela n. I, anexa à Lei 3.097, de 29 de dezembro de 1972, as sociedades que pratiquem o culto Afro-Brasileiro, como forma exterior da religião que professam, que assim podem exercitar o seu culto, independentemente de registro, pagamento de taxa ou obtenção de licença junto a autoridades policiais.

Art. 2o Este decreto entrará em vigor na data de sua publicação, revogadas as disposições em contrário.

Palácio do Governo do Estado da Bahia, 15 de janeiro de 1976.

ROBERTO FIGUEIRA SANTOS

Odeere: revista do programa de pós-graduação em Relações Étnicas e Contemporaneidade - UESB. ISSN 2525- 4715. Ano 2, número 3, volume 3, Janeiro - Junho de 2017. 
Egungum da morte interrompera a vida durante um ano, afugentando os deuses da África; mas, após os ritos programados, seguidos de missas na igreja dos Agostinianos, os deuses desceriam e dançariam novamente e permitiriam que o sacerdócio funcionasse em toda sua capacidade ${ }^{9}$.

O papel organizador, aglutinador e disseminador das mulheres do candomblé na mobilização da comunidade fortalece a função midiática demonstrando o prestígio que se dá no reconhecimento de uma prática religiosa historicamente perseguida.

Historicamente, na Bahia, a mulher negra teve um papel significativo, dada a dimensão que mães-de-santo como Pulquéria, Aninha, Senhora e Emiliana do Bogum tiveram nos terreiros de tradição feminina. Nesses terreiros (de maior expressão), somente a mulher pode participar do processo de eleição para cargo supremo, com um poder ilimitado, de acordo com a vontade dos Orixás, como creem os seguidores do candomblé ${ }^{10}$.

O reconhecimento do papel de liderança da mulher negra no candomblé como mãe de santo, sacerdotisa máxima do templo foi uma conquista frente a uma conjuntura de inferiorização do homem negro marcada pela lógica machista imposta pelo homem branco e pela sociedade racista.

A atuação da mulher negra na sustentação de alguns templos da religiosidade de matriz africana foi fundamental na manutenção do culto aos inquices, voduns e orixás até a atualidade como também no processo de inserção do mesmo tendo na figura da mãe de santo mais do que uma líder religiosa e sim uma liderança política e social.

A mulher sempre teve uma importância grande no candomblé da Bahia em razão da própria estrutura social que excluía o homem africano escravizado de exercer uma função pública de tamanha importância e poder em uma sociedade machista como a baiana e a brasileira.

A razão do machismo na sociedade não é a única que explica a ascensão da mulher no processo ritualístico do candomblé, mas também o fato de ser um grupamento que estava sofrendo pressões políticas, culturais e sociais.

\footnotetext{
${ }^{9}$ (LANDES, 2002, p. 279).

${ }^{10}$ (JOAQUIM, 2001, p.15).
}

Odeere: revista do programa de pós-graduação em Relações Étnicas e Contemporaneidade - UESB. ISSN 2525- 4715. Ano 2, número 3, volume 3, Janeiro - Junho de 2017. 
Havia e ainda há um racismo, um preconceito e uma discriminação no tratamento do poder público as atividades exercidas e desempenhadas no interior de um terreiro de candomblé como uma afronta ao atual modelo civilizatório dominante.

Este comportamento faz com que os terreiros se transformem em verdadeiras famílias tendo o agente feminino como principal instrumento de aglutinação entre os adeptos e frequentadores de cada instituição.

O papel de mãe é identificado, segundo Mãe Cidália, com a África, onde existe a terra fértil de valores culturais, tradições, passando aos afrobrasileiros uma maneira negra de viver. Acrescido ao significado do papel de mãe encontra-se o fator de dar a vida, fazer o Santo, ou seja, o acesso à comunicação com os Orixás, que se complementa com os adjetivos de provedora, acolhedora, educadora. Enfim, é quem fornece o aconchego a todas as pessoas ${ }^{11}$.

O papel do acolhimento desempenhado pela mulher é associado com a própria ideia de África que irá até as origens de onde estas populações que foram escravizadas são oriundas, trazendo o papel de grupo, de conjunção e de proteção.

No poema, encontra-se em primeiro lugar o modelo histórico no qual se inspira o personagem ritual atual. Trata-se da escrava mãe de leite dos pequenos senhores brancos, integrada na casa grande do senhor, mas à margem da estrutura familiar. O personagem da ama preta é uma herança do sistema escravista na sua forma mais opaca, aquela das relações de facea-face na família patriarcal. Nelas, a dominação do senhor branco - e de sua esposa legítima e branca - podia ser colocada em dificuldade pelos micropoderes domésticos da ama preta, fossem aquelas da cozinha, da sedução sobre o senhor ou da dependência infantil. A homenagem paternalista à Mãe Preta é, pois, inscrita na história da escravidão com uma função compensatória e reguladora das relações internas à casa grande e ao sobrado. Réplica feminina da figura do velho escravo resignado (Pai João), imagem envelhecida (e amadurecida) da Negra Fulô, a Mãe Preta está associada, na memória e na poesia popular, à ternura e ao sofrimento ${ }^{12}$.

A importância e força das mulheres do candomblé se dá em um contexto de profunda adversidade e subjugação marcado por uma criminalização das práticas culturais da população negra do país como a capoeira, o candomblé, o acarajé e outras produções vindas e elaboradas

\footnotetext{
${ }^{11}$ (JOAQUIM, 2001, p.15 e 16).

${ }^{12}$ (AGIER, 1996, p. 197).
}

Odeere: revista do programa de pós-graduação em Relações Étnicas e Contemporaneidade - UESB. ISSN 2525- 4715. Ano 2, número 3, volume 3, Janeiro - Junho de 2017. 
pela matriz africana ou a participação direta de indivíduos negros em competições públicas que eram excluídos pelo racismo institucional.

Esta homenagem paternalista a mãe preta e ao que a mesma representa deseja o retorno desta subjugação em um momento histórico atual de mudanças no tratamento que o poder público e a sociedade trata o candomblé hoje com um valor cultural importante para a cultura nacional e necessita de entendimento, preservação e cuidado.

Esta afirmação marcada pela escravidão e as relações que a mesma produziu como a casa grande e a senzala com a presença da réplica feminina da figura do velho escravo resignado, o pai João, com a imagem envelhecida e amadurecida da Negra Fulô, a mãe Preta está associada, na memória e na poesia popular, à ternura e ao sofrimento.

É neste contexto que vai acontecer à atuação das mulheres, sejam elas, negras, brancas, índias, mulatas em uma cidade pequena marcada pelo transporte do trem e pelo movimento do rio Paraguaçu, com pessoas de maioria católica e evangélica que se ocupa de atividades agrícolas e rurais.

A importância das mulheres no fortalecimento do candomblé e como a mesma influencia no desenvolvimento de uma cidade como Cachoeira com os atuais níveis de violência e desemprego deve ser enfatizado também a função dos papéis exclusivamente ocupados por mulheres e a importância religiosa destas para o funcionamento do culto e também a importância destas mulheres como mães biológicas de iniciados (as) no candomblé.

Sendo que o papel feminino ultrapassa a relação biológica da criação, indo ao protagonismo através da realização de atividades e eventos que trazem ao seio de uma organização dirigida por elas.

Esta construção e afirmação teve a mulher negra como principal protagonista em um ambiente de perseguição e violação de direitos em que o machismo imperava e o poder era exclusivamente masculino, pois em alguns casos as mulheres não tinham direito ao voto e não tinham direito de voz e de representação.

A importância da mulher para o candomblé por meio de papéis religiosos, hierárquicos e administrativos no interior dos terreiros de candomblé é crucial para a transmissão do legado da religião para as futuras gerações. 
O papel da "equéde ${ }^{13 "}$, da "iamorôn", da "ialorixá15" e de outros postos ocupados exclusivamente por mulheres no interior do candomblé demonstra a importância e a sua capacidade em resolver problemas. O papel da mulher na afirmação do candomblé foi crucial contribuindo com sua afirmação e institucionalização.

A importância das mães de santo está relacionada ao crescimento da importância das sacerdotisas no fortalecimento e divulgação da religião do candomblé e como as suas lideranças religiosas são fundamentais para a sobrevivência do culto.

\section{As mulheres, o candomblé e o desenvolvimento de Cachoeira}

Cachoeira possui uma história de aproximação e reprodução dos valores culturais de matriz africana marcado pelas músicas do grupo "os tincoãs ${ }^{16 "}$ nos anos setenta e o mais recente grupo de música afro-sacra "gêge nagô" que já apresentou-se com artistas como Margareth Menezes ${ }^{17}$ desde a migração de mães de santo oriundas do Recôncavo Baiano e que vão se instalar no Rio de Janeiro com a saudosa "Mãe Beata ${ }^{18}$ de lemanjá ${ }^{19 "}$ e "Mãe Neinha ${ }^{20}$ de Nanã ${ }^{21 "}$ no estado de São

\footnotetext{
${ }^{13}$ Função no candomblé exercida somente por mulheres. Forma abrasileirada do termo ekéde (conforme Houaiss). (LOPES, 2004, p. 255). Ekéde. Nos candomblés, cargo sacerdotal feminino correspondente ao do ogã. Nas festas públicas, a ekéde é quem recepciona os orixás incorporados, cuidando de suas vestes, enxugando o suor do rosto da iaô etc. do ioruba ékejí, "acompanhante". (LOPES, 2004, p. 248).

${ }^{14}$ Função no candomblé exercida somente por mulheres. Sacerdotisa auxiliar da ialorixás. Do iorubá lyá mòró, título nobiliárquico do palácio de Oyó, dado a pessoas da família do Basórun, ministro do rei. (LOPES, 2004, p. 333).

${ }^{15}$ Função no candomblé exercida somente por mulheres. Denominação que no Brasil se dá a sacerdotisa-chefe de uma comunidade -terreiro, o mesmo que mãe-de-santo. Do iorubá iyalorisa. (LOPES, 2004, p. 333).

${ }^{16}$ Grupo musical de Cachoeira que fez muito sucesso na década de 1970 exaltando a música negra.

${ }^{17}$ Cantora baiana de expressão nacional e internacional.

${ }^{18}$ Sacerdotisa de Cachoeira que organizou um terreiro de candomblé no Estado do Rio de Janeiro.

${ }^{19}$ Deusa das águas salgadas no candomblé, mãe da criação do mundo. Grande orixá feminino das águas, reverenciada, no Brasil, como mãe de todos os orixás. lemanjá na África: Filha de Olókun, divindade do mar, Yemója é o nome tutelar do rio Ógún, que passa pela cidade de beokutá e desemboca em frente à cidade de Lagos, na Nigéria. Segundo os mitos, nasceu perto da cidade de Bidá, no território do povo Nupê, e se mudou para Oió, onde casou com Óranían e deu à luz Xangô. Seu símbolo é um colar de continhas de vidro, cristalinas "como água". Sobre ela, escreve Pierre F. Verger: "lemanjá cujo nome deriva de Yeyé como ejá ("Mãe cujos filhos são peixes") é o orixá dos Egbás, uma nação ioruba estabelecida outrora na região entre Ifé e Ibadan, onde existe ainda o rio Yemoja. As guerras entre nações iorubás levaram os Egbás a emigrar na direção oeste, para Abeokutá, no início do século XIX. Evidentemente não lhes foi possível levar o rio, mas em contrapartida transportaram consigo os objetos sagrados, suportes do axé da divindade e o rio Ógún, que atravessa a região, tornou-se, a partir de então, a nova morada de lemanjá". lemanjá nas Américas: No Brasil, segundo Verger, são conhecidas as seguintes qualidades de lemanjá: Assabá, que é manca e está sempre fiando algodão; Assessu, muito voluntariosa e respeitável; Euá; lamassê, mãe de Xangô; lemouô, mulher de Oxalá; Olossá, que é o nome de uma lagoa africana; e Ogunté, casada com Ogum Alabedé. (LOPES, 2004, p. 335).
}

Odeere: revista do programa de pós-graduação em Relações Étnicas e Contemporaneidade - UESB. ISSN 2525- 4715. Ano 2, número 3, volume 3, Janeiro - Junho de 2017. 
Paulo, fortalecendo a rede de candomblé do povo de Cachoeira com destaque para o papel feminino, sendo que esta pode estabelecer várias escalas desde a regional, a nacional e até a internacional.

Um grande exemplo da força da mulher em Cachoeira é a atuação da Irmandade de Cor da Nossa Senhora da Boa Morte ${ }^{22}$ com um grande tempo de existência e este foi o motivo de iniciarmos os exemplos de experiências das mulheres a frente de organizações que desempenham um importante papel no território com a irmandade pela sua resistência e luta no território de Cachoeira.

A Irmandade de Nossa Senhora da Boa Morte está entre as mais antigas do país, tendo surgido nas primeiras décadas do século XIX, possivelmente por volta de 1820, nas proximidades da Barroquinha, em Salvador ${ }^{23}$, de onde, anos mais tarde, migrou para Cachoeira, respondendo, atualmente, pelo endereço Rua 13 de Maio ${ }^{24}$.

Esta instituição que existe desde 1820 iniciada na cidade de Salvador no bairro da Barroquinha completou 192 anos de existência e com isto demonstra o longo período de resistência e experiência desta entidade.

Essas irmandades de cor recebiam africanos (as) escravizados (as) de várias origens trazidos ao Brasil em advento da Escravidão e em sua maioria eram sudaneses, como os iorubás, ewes e haussas, todas etnias africanas.

Os Africanos trazidos ao Brasil eram de origens diversas: os que chegaram em Salvador eram, em sua maioria, sudaneses, como os iorubas, os Ewes e os Haussas, enquanto que nas regiões rurais eram sobretudo bantos, como os Congos e os Angolas, como se chamavam de maneira genérica. Segundo

\footnotetext{
${ }^{20}$ Sacerdotisa de Cachoeira que organizou um terreiro de candomblé em uma cidade no estado de São Paulo.

${ }^{21}$ Deusa dos mangues e águas profundas no candomblé. Nanã. Redução de Nanã Borocô.; Nanã Borocô. Variação de Nanã Burucu.; Nanã Borutu. Variação de Nanã Burucu.; Orixá de origem jeje ou vodum, cultuado na mina, no candomblé e na umbanda. Na África, é a divindade cultuada da antiga lorubalândia até a região dos tapas, além do rio Volta, na região dos Guangs, e até o território dos Axantis. Entre estes, Nanã é o termo de deferência para pessoas idosas e respeitáveis. O povo bambara, do Mali, cultua uma entidade chamada Nan-Woloko, nome de sonoridade semelhante a Nanã Borocô. Para os iorubas de Kêtu, Nanã Buruku é a mãe mais antiga, representada pelas águas paradas dos lagos e pela lama dos pântanos, de onde tudo se originou; é o princípio da fertilidade, enfim. (LOPES, 2004, p. 446).

${ }^{22}$ A população de cor se vinculava a várias irmandades ao mesmo tempo e ela legava suas economias para ter enterros decentes, às vezes com um grande cortejo e com numerosas missas. Os negros e mulatos copiavam desta maneira as decisões testamentárias efetuadas pelos brancos ricos (Reis, 1991). (VASCONCELOS, 1997, p. 16).

${ }^{23}$ (TAVARES, 1964, p.235)

${ }^{24}$ (CASTRO, 2005, p. 45).
}

Odeere: revista do programa de pós-graduação em Relações Étnicas e Contemporaneidade - UESB. ISSN 2525- 4715. Ano 2, número 3, volume 3, Janeiro - Junho de 2017. 
sua região de origem, eles eram nômades, agricultores sedentários ou criadores, ou ainda, artesões ou comerciantes e habitavam nas cidades ou vilas, como os iorubas ou Haussas ${ }^{25}$.

Isto demonstra a ligação direta que as irmandades de cor tinham com as nações africanas que foram exploradas no processo de formação do Colonialismo, Imperialismo e Capitalismo e que os seus descendentes, os africanos escravizados e seus descendentes organizavam suas relações no Brasil.

O exemplo de sua atuação que na sua fundação em 1820 tinha uma função de receber e agregar membros de nações africanas demonstra que houve uma comunicação entre religiões e rituais, a igreja católica e o candomblé?

Mas em 1820 o candomblé não existia ainda como instituição e somente em 1860 vai se constituir como se apresenta nos dias atuais e daí é que vem a pergunta, se o candomblé é uma instituição criada no Brasil, de que forma estas mulheres influenciaram nesta formação também? Já que no candomblé o poder feminino foi conquistado e consolidado.

Havia irmandades exclusivas de Africanos: a da Boa Morte era uma irmandade feminina ioruba que tinha sede na igreja da Barroquinha, fora da antiga porta da cidade, lado $\mathrm{sul}^{26}$.

O importante nesta construção é atentar o Cachoeira vai galgar uma maior importância em 13 de março de 1837 ao deixar de ser vila e ser considerada cidade por meio da lei provincial 44, indicando que 13 anos depois as irmãs estariam se instalando na cidade de Cachoeira em 1850.

A existência de irmandades exclusivas de africanos a da Boa Morte era uma irmandade feminina iorubá instalada em uma localização central na capital da Bahia e que posteriormente foi transferida para Cachoeira ${ }^{27}$.

Considera-se, aqui, que a transferência da Irmandade da Boa Morte para a cidade de Cachoeira ocorreu por volta de 1850. De todo modo, tal mudança ocorreu num momento histórico em que a economia açucareira da primeira metade do século XIX proporcionou aos senhores de engenho do

\footnotetext{
${ }^{25}$ (VASCONCELOS, 1997, p. 16).

${ }^{26}$ (VASCONCELOS, 1997, p. 15).

${ }^{27}$ A irmandade ainda existe em Cachoeira, a $100 \mathrm{Km}$ de Salvador. (VASCONCELOS, 1997, p. 15).
} 
Recôncavo, um grande poderio econômico, político, além de muito prestígio junto aos demais senhores da aristocracia baiana. Fatos estes, que explicam o alto número de escravos nesta região, e, conseqüentemente, uma considerável variedade étnica em suas fazendas ${ }^{28}$.

A transferência da irmandade da Boa Morte de Salvador para Cachoeira em torno de 1850 em um período marcado por uma conjuntura de mudança em que a economia açucareira da primeira metade do século XIX proporcionou aos senhores de engenho do Recôncavo Baiano ${ }^{29}$ um grande poderio econômico, sendo um período áureo desta região e de Cachoeira.

Com o aumento da influência dos senhores de engenho através do prestígio com a aristocracia baiana demandavam uma quantidade maior de escravos em suas fazendas e a garantia de uma grande diversidade étnica de indivíduos oriundos de várias civilizações africanas.

A Irmandade concentra toda a sua organização no poder feminino criando uma tradição que atravessou séculos e ao invés de ser extinta ganhou força e o reconhecimento da sua importância por meio de investimentos públicos.

As irmandades de cor numa sociedade baseada na segregação, e em pleno período escravagista, a alternativa para a população de cor, escrava e livre, era a de criar suas próprias irmandades. Essas irmandades possuíam capelas nas grandes igrejas ou, ainda, suas próprias capelas e igrejas, encomendadas aos mestres artesoes. Elas realizavam empréstimos de ajuda mútua e adiantamentos para a realização das alforrias ${ }^{30}$.

Em uma sociedade baseada na segregação uma irmandade de cor representava bem esta postura de união em um período escravagista, assim a população de cor, escrava e livre criava suas próprias irmandades como alternativa de sobrevivência social e política que atuava por meio das suas próprias capelas e igrejas e como também realizavam empréstimos de ajuda mútua e adiantamentos para a realização das alforrias ${ }^{31}$.

\footnotetext{
${ }^{28}$ (CASTRO, 2005, p. 50).

${ }^{29}$ Este período marcado pela abundância construiu um patrimônio arquitetônico e cultural caracterizado pela existência de templos religiosos como igrejas, irmandades religiosas, terreiros de candomblé e demais objetos urbanos que construíram a urbanidade do Recôncavo e especificamente de Cachoeira. (CORREIA, 2015, p. 136,137). ${ }^{30}$ (VASCONCELOS, 1997, p. 14).

${ }^{31}$ Alforria: Ato pelo qual cessava o estado de escravidão. No Brasil, a alforria, conseguida por compra, doação ou imposição legal, podia ser feita por carta, no caso do escravo adulto que comprava ou recebia gratuitamente a liberdade, por testamento, na circunstância de o escravo ser declarado manumisso no testamento do proprietário
}

Odeere: revista do programa de pós-graduação em Relações Étnicas e Contemporaneidade - UESB. ISSN 2525- 4715. Ano 2, número 3, volume 3, Janeiro - Junho de 2017. 
A irmandade da Boa Morte se instalava em Cachoeira em torno de 1850, 13 anos depois da transformação da vila em cidade e em 2016 com 192 anos de fundada e com 167 anos de funcionamento na cidade cachoeirana acumula uma experiência na mediação de conflitos, sendo que em 1970 quase fecha suas portas na crise e no declínio da economia do Recôncavo Baiano.

No Brasil o candomblé irá se apresentar com características de um certo nível de institucionalização em 1860, segundo Nicolau Parés com seus ritos e mitos estruturados como se encontram nos dias atuais.

Se na década de 1830 já existem claros indícios de congregações extradomésticas com um significativo grau de complexidade social e ritual, a documentação do O Alabama não deixa dúvida que na década de 1860 o Candomblé tinha atingido um nível de institucionalização comparável ao que conhecemos hoje em dia. Além das frequentes atividades de cura e adivinhação mantidas por especialistas religiosos individualizados, havia uma extensa rede de congregações religiosas, com espaços sagrados relativamente estáveis, tanto nas roças da periferia como no centro urbano, que mantinham variadas relações de cooperação e complementaridade. Essas congregações estavam organizadas conforme uma hierarquia que derivava do princípio de senioridade, estabelecido através de demorados processos de iniciação ${ }^{32}$.

Sendo que o Candomblé irá construir características socialmente identificadas de forma coletiva a partir de 1860 em que turbantes, contas e outros adereços que identificam os seus adeptos irão modelar parte da sua construção.

Essa população infantil, oriunda da escravidão e filha de vodunsis e ogans do candomblé de tio Anacleto, seria a geração que garantiria o futuro da tradição afro-religiosa do engenho Natividade e a descendência de Anacleto. O candomblé de tio Anacleto era um elo importante na constituição de uma rede de sociabilidade e religiosidade que ligava filhos de africanos a várias comunidades de candomblé de Cachoeira. Referi-me acima a Maria Militana e Josefa da Conceição, filhas de Anacleto, residindo, no final do século XIX, na Recuada, libertas, exercendo função de quitandeiras. Essas mulheres, como várias outras que em 1856 eram escravas ainda crianças e adolescentes, do engenho Natividade, após a

falecido; de pia, quando a libertação ocorria no ato do batismo católico, mediante o pagamento, ao dono do escravo, de uma quantia previamente estipulada. Outra forma de concessão da alforria era a carta de liberdade condicional, na qual o outorgante estipulava a libertação do escravo em data determinada, por exemplo, para depois do falecimento do proprietário. (LOPES, 2004, p. 49).

32 (PARÉS, 2007, p. 142/143).

Odeere: revista do programa de pós-graduação em Relações Étnicas e Contemporaneidade - UESB. ISSN 2525- 4715. Ano 2, número 3, volume 3, Janeiro - Junho de 2017. 
abolição eram consideradas mulheres do partido alto e respeitáveis senhoras da Irmandade da Boa Morte ${ }^{33}$.

Este período entre 1856 e 1860 que foi fundamental por existir uma interação entre os territórios de Cachoeira e São Félix e estabeleceu uma identidade para o candomblé com uma participação efetiva das mulheres e da Irmandade da Boa Morte.

Assim, as irmãs da Boa Morte farão uma ponte importante entre os territórios religiosos do candomblé e da Igreja Católica estabelecendo um diálogo inter-religioso que irá influenciar na dinâmica.

Acompanhando a crise e declínio de parte do Recôncavo Baiano na década 1970, a Irmandade da Boa Morte, neste período, quase fechou suas portas. A falta de recursos e incentivo dos órgãos oficiais - em nível local, estadual ou federal - e as modestas proporções do quadro de irmãs acentuaram a crise na Irmandade, que, por muitas décadas, realizou com recursos próprios as suas festividades. Tais recursos advinham de doações da sociedade, economias e donativos de algumas irmãs, entre outros ${ }^{34}$.

Mesmo com a crise da economia do Recôncavo em 1970 a irmandade da Boa Morte demonstrou sua capacidade de articulação e mesmo sem recursos financeiros e a falta de incentivo dos órgãos oficiais nos níveis municipal, estadual e federal a instituição não teve o seu funcionamento interrompido.

As festividades, mesmo com a degradação econômica da região, foram realizadas, e que por muitas décadas forneceu recursos por meio de doações da sociedade, economias e donativos de algumas irmãs e outras estratégias de manutenção sendo um período considerado difícil frente a crise econômica de todo o Recôncavo Baiano, mas a irmandade continuou resistindo e sobrevivendo.

Mas um episódio teve grande impacto na história da irmandade que foi a queima de arquivos, por parte de uma irmã da seguinte forma:

Não bastasse esta desventura no campo documental, a Boa Morte assistiu, na década de 1980, ao episódio em que uma de suas mais antigas irmãs -

\footnotetext{
33 (NASCIMENTO, 2010, p. 165).

${ }^{34}$ (CASTRO, 2005, p. 47).
} 
nome não divulgado -, em virtude de sua idade avançada ou de desgaste mental, ateou fogo em um dos livros de fundação da Irmandade ${ }^{35}$.

A década de 1980 foi marcada por um conjunto de fatos, que causaram uma espécie de abalo na estrutura organizativa que em primeiro ocorre com um problema relacionado a um membro acusando desgaste mental ou idade avançada e o outro um grande incêndio na Igreja da Barroquinha.

É como se o destino tivesse reservado à Irmandade da Boa Morte um roteiro de fé, prestígio, mas, também, de luta e falta de documentação. 0 incêndio da Igreja da Barroquinha em 1984 deixou em ruínas o prédio e os arquivos que poderiam comprovar se, no passado, a Irmandade da Boa Morte teve seus estatutos aprovados pelas autoridades eclesiásticas. Esta situação também foi averiguada e confirmada junto aos arquivos da Cúria Metropolitana de Salvador ${ }^{36}$.

Já em 1984 o incêndio que deixou em ruínas os prédios e os arquivos com documentos que comprovavam a aprovação dos seus estatutos por parte das autoridades eclesiásticas atrasou sua regularização nos novos tempos da transição para o regime da Ditadura para a Democracia.

Mesmo sendo uma irmandade da Igreja Católica boa parte das irmãs pertencem ao candomblé e fortalecem essas identidades por meio dos rituais, das roupas e adereços que adornam a indumentária de toda a festa de Nossa Senhora da Boa Morte que ocorre em todo mês de agosto.

No episódio vivido com a Igreja Católica em que houve uma fragilização na relação com as irmãs em 1989 irá mostrar um fortalecimento desta instituição, a irmandade com a construção de uma efetiva autonomia e independência por meio da tradição.

Como mandava a tradição, a festa da Boa Morte foi realizada com toda pompa entre os dias 18 e 20 de agosto de 1989. Os fatores discutidos no capítulo 2, entretanto, nos fazem acreditar que, apesar da aparente normalidade dos festejos, o clima era tenso. O furto no Museu das Alfaias (1987), a aliança entre a Irmandade e o novo prefeito, que se opunha ao padre, e o recebimento de doações à revelia do padre, eram alguns dos elementos que contribuíam para tensionar as relações entre a Igreja e a Irmandade. Ademais, uma devoção permeada de elementos da cultura e

\footnotetext{
35 (CASTRO, 2005, p. 49).

${ }^{36}$ (CASTRO, 2005, p. 49).
} 
religiosidade africanas parecia incompatível com um pároco envolvido num projeto neoromanizante ${ }^{37}$.

Desde o roubo dos Alfaias em 1987 que iniciava um clima de tensão e em conjunto de situações que demonstraram autonomia e liderança como a aliança entre a irmandade e o novo prefeito e o recebimento de doações sem o controle da Igreja Católica que era representada pelo padre que irá demonstrar liberdade política.

Como se não bastasse o fato de ser uma irmandade de cor identificava a devoção permeada de elementos da cultura e religiosidade africanas parecendo ser incompatível com os interesses católicos.

Assim, os preparativos da festa neste ano de 1989 irá ratificar a independência e liberdade conquistadas com a tradição da Irmandade da Boa Morte com autonomia inclusive política ao conversar diretamente com poder político da cidade, o prefeito, que irá fazer da irmandade uma referência de identidade.

Este episódio ao invés de enfraquecer a Irmandade a projetou internacionalmente criando uma comoção que alcançou territórios de fora do Brasil fortalecendo assim o intercâmbio entre afro-americanos pan-africanistas e afro-brasileiros por meio da Irmandade da Nossa Senhora da Boa Morte.

${ }^{37}$ (SOUZA, 1989, p. 94).

Para apimentar ainda mais as relações entre as duas instituições, entre os dias 9 e 10 de agosto daquele ano, a Irmandade registrou em cartório um novo estatuto e adquiriu personalidade jurídica frente à Receita Federal. Um verdadeiro ato de rebeldia e independência, apenas alguns dias antes da Festa de Nossa Senhora da Boa Morte.

Apesar de todos esses pontos de tensão, um observador menos informado, poderia ter dito que as festividades tiveram o brilho de sempre. A imprensa, por exemplo, mais uma vez noticiou e elogiou a festa, omitindo qualquer problema. As missas e procissões transcorreram como de costume. Os banquetes foram servidos e o samba-de-roda animadamente cantado e dançado. Havia um número recorde de turistas na cidade, com destaque para os 400 norteamericanos que acompanharam as festividades. Barracas estavam espalhadas por toda a Rua 25 de Junho e havia até um trio elétrico enviado por um político. A imprensa escrita ressaltou a estreita ligação entre a Irmandade e o Candomblé, afirmando que uma linha muito tênue separava uma religião de outra, por isso não se sabia direito quando uma

Odeere: revista do programa de pós-graduação em Relações Étnicas e Contemporaneidade - UESB. ISSN 2525- 4715. Ano 2, número 3, volume 3, Janeiro - Junho de 2017. 
terminava e a outra começava; acrescentando ainda que a missa de corpo presente, celebrada no sábado à noite, na verdade era para Egum ${ }^{38}$.

Com o seu registro em cartório de um novo estatuto adquiriu pessoa jurídica frente a Receita Federal afirmando a sua independência e mesmo com todos estes pontos de conflito a festa foi marcada por muita alegria e positividade.

Recebendo elogio da imprensa e omitindo qualquer problema os banquetes foram servidos e as missas e procissões ocorreram como nos anos anteriores e o tradicional samba-de-roda cantado e dançado foi apresentado.

Este ano o destaque foi para os quatrocentos turistas norte-americanos que estavam na cidade para acompanhar as festividades que demonstrou a expansão e influência das irmãs que foram agraciadas com a visita de turistas estrangeiros em grande número globalizando o roteiro da festa e mostrando o seu caráter cosmopolita.

A afirmação da identidade de matriz africana foi fortalecida ao momento em que a imprensa ressaltou a estreita ligação entre a irmandade e o candomblé, reconhecendo que uma linha muito tênue separava uma religião da outra, chegando ao ponto de não se saber com exatidão onde começava uma ou onde terminava a outra, acrescentando ainda que a missa realizada era na verdade uma celebração para egum ${ }^{39}$.

A situação em questão será resolvida no último ano da década de 1990, com o retorno da Igreja Católica na participação dos rituais que compõem a festa da Irmandade, restabelecendo a ação de coexistência pacífica entre os territórios, entretanto, uma "paz" que permanece perpassada pela instabilidade ditada pelo jogo de poder que se estabelece e pelo sentido do ato de festejar da Boa Morte, atendendo, desta forma, as duas ações fundamentais deste jogo, isto é, sob o registro religioso e sob o registro político ${ }^{40}$.

A década de 1990 se revela para a irmandade como um momento de fortalecimento de identidades, principalmente a de matriz africana, quando irá encorajar as irmãs em admitir não somente a sua importância religiosa, mas também a política.

\footnotetext{
${ }^{38}$ (SOUZA, 1989, p. 94).

39 Egum: Espírito, alma de morto. Do iorubá égun, “osso", “esqueleto”. (LOPES, 2004, p. 251).

${ }^{40}$ (CORRÊA, 2008, p.12).
} 
Ao analisar o território mítico-religioso da Irmandade da Boa Morte, em Cachoeira, na Bahia como reorganização social e política, distingue ${ }^{41}$ "duas territorialidades de distintas práticas culturais". A autora ressalta a territorialidade aparente, operada por meio da prática do catolicismo brasileiro, e a territorialidade subjacente da prática do candomblé, que "fortalece o elo entre as componentes da Irmandade", reforçando a identidade afro-brasileira no lugar e, consequentemente, no sentido de pertencimento da comunidade religiosa ${ }^{42}$.

A distinção entre as "duas territorialidades de distintas práticas culturais" operada por meio da prática do catolicismo brasileiro, e a territorialidade subjacente da prática do candomblé fortalecendo o elo entre as componentes da irmandade e reforçando a identidade afro-brasileira no lugar irá desmistificar o sincretismo religioso e irá acentuar a necessidade de visibilidade política.

O papel desempenhado pelas irmãs na articulação e na mobilização de forças para o reconhecimento da importância desta tradição demonstra a capacidade das mulheres em operar com instrumentos políticos, sociais e midiáticos.

Esta atuação das componentes da irmandade da Boa Morte é um dos aspectos da atuação das mulheres do candomblé, mas, por outro lado existiram iniciativas individuais de lideranças femininas demonstradas no capítulo IV intitulado "As Senhoras do Segredo: lutas, encantos e desencantos na resistência dos candomblés" do livro "O poder dos candomblés" 43 retrata vários episódios. Dando destaque a atuação de Mãe Judith como cita abaixo:

No que concerne às mulheres participantes do culto aos voduns e orixás, na maioria das vezes o jornal as trata como prostitutas que viviam em "pândegas e orgias com ogans e pais-de-santo". Mulheres promíscuas dando mau exemplo "às moças e senhoras de família". Os episódios em que esteve em cena a lalorixá Judith demonstram um pouco desse tratamento. Mãe Judith, como já nos referimos, foi uma das ialorixás mais perseguidas pelo jornal A Ordem. Entre os anos de 1914 e 1923, ela figurou com frequência nas páginas deste periódico. Mãe Judith atuou em cenas que o periódico classificou de "um ultraje a família cachoeirana ${ }^{44}$.

\footnotetext{
${ }^{41}$ Corrêa (2004)

42 (ROSENDAHL, 2013. p. 110).

${ }^{43}$ (SANTOS, 2009)

${ }^{44}$ (SANTOS, 2009, p. 134).
}

Odeere: revista do programa de pós-graduação em Relações Étnicas e Contemporaneidade - UESB. ISSN 2525- 4715. Ano 2, número 3, volume 3, Janeiro - Junho de 2017. 
A presente matéria do jornal "A Ordem" revela o tratamento preconceituoso e discriminatório por parte da imprensa que irá tratar as mulheres que participam do culto aos voduns e orixás como prostitutas que viviam em "pândegas e orgias com ogans e pais de santo". Referindo-se ainda a estas como promíscuas e que eram mau exemplo "as moças e senhoras de família".

Este jornal entre os anos de 1914 e 1923, parte do período da I guerra mundial, estabeleceu uma perseguição sistemática aos terreiros de candomblé classificando o seu ritual como "um ultraje a família cachoeirana".

A lalorixá Judith se apresenta como uma liderança religiosa demonstrando prestígio entre os demais sacerdotes e demais sacerdotisas estabelecendo assim uma espécie de interlocução pública entre os terreiros de candomblé de Cachoeira e outros do Recôncavo Baiano.

O jornal A Ordem publicou diversos editoriais onde as mulheres aparecem como categoria da qual os homens dispõem, no sentido de lhes fornecer princípios morais para a boa convivência na família e na sociedade. De maneira geral, as mulheres não figuravam nos artigos e notícias do periódico, à exceção se fazia quando os valores "morais" e "civilizatórios" eram colocados em risco, segundo as considerações dos articulistas. Então, títulos como "A missão da mulher", "A mulher e a virtude", "A mulher e o cristianismo" ou "A mulher e a família", ocupavam longos e disciplinadores editoriais. Na mesma sintonia foi possível encontrar, ocupando não menos espaço na primeira página, muitos artigos denunciando "os crimes da feitiçaria" e consequentemente as feiticeiras ${ }^{45}$.

O Jornal "A Ordem" irá continuar publicando em seus inúmeros editoriais títulos como "A missão da mulher", "A mulher e a virtude", "A mulher e o cristianismo", "A mulher e a família" com o objetivo de fortalecer campanhas com princípios morais para a boa convivência na família e na sociedade.

Tal campanha tinha como foco a desqualificação da mulher do candomblé e que ocupava uma liderança e que se posicionava contra o sistema vigente e que atuava no combate às desigualdades da época.

\footnotetext{
${ }^{45}$ (SANTOS, 2009, p. 133).
} 
Entre o período de 1920 a 1930 Aurélio da Matta, pai da senadora pela Bahia na República Federativa do Brasil (Mandato 2010 - 2018) liderava em Cachoeira um movimento revolucionário formado por camponeses comunistas do Iguape e o lugar que se realizavam as reuniões deste movimento revolucionário era o terreiro de tia Judite.

A realização das reuniões do movimento revolucionário no terreiro de mãe Judite irá fazer com que haja um posicionamento político para com questões contrárias ao Estado Brasileiro sendo justificada a partir daí uma perseguição ao terreiro e as suas lideranças.

Com um destaque equivalente nos artigos vinculados pelo jornal "A Ordem" com espaço na primeira página estava denunciando "os crimes de feitiçaria" e incentivando a perseguição as feiticeiras que eram associadas as sacerdotisas do candomblé.

\begin{abstract}
A julgar pelas notícias do jornal A Ordem, as mulheres constituíam a grande maioria das lideranças dos candomblés de Cachoeira nas três primeiras décadas do século XX. Os candomblés, por seu turno, representavam para setores letrados locais o "africanismo barato", "os bródios", "as orgias", liderados por mulheres de "baixa candura" e "degeneradas". Essas mulheres eram representadas como o avesso do ideal patriarcal exaltado nos editoriais da folha ${ }^{46}$.
\end{abstract}

As perseguições por parte deste veículo de comunicação a grande maioria das lideranças do candomblé de Cachoeira continuam nas três primeiras décadas do século XX por meio de adjetivos que se referem ao culto como "africanismo barato", "bródios" e "as orgias".

Por sua vez, as matérias vinculadas colocavam essas mulheres do axé como de "baixa candura" e "degeneradas", na maioria das vezes, associadas ao avesso da civilidade, a incivilidade, sendo a contramão da moral e dos bons e costumes.

Essa campanha negativa da religiosidade de matriz africana por parte da imprensa irá criar um fetiche de inferioridade em torno do debate público que envolvia e envolve os padrões de civilidade que irão ditar os comportamentos sociais e os demais revelando a existência do preconceito, da discriminação e do racismo.

${ }^{46}$ (SANTOS, 2009, p. 135).

Odeere: revista do programa de pós-graduação em Relações Étnicas e Contemporaneidade - UESB. ISSN 2525- 4715. Ano 2, número 3, volume 3, Janeiro - Junho de 2017. 
Em um período de criminalização das práticas culturais de matriz africana só havendo a desobrigação do pedido de licença na delegacia de jogos e costumes no Decreto estadual de no 25.095 de 13 de janeiro de 1976.

Período que até o ano de 1976 foi marcado por uma perseguição sistemática que feria profundamente a autonomia e a liberdade do culto do candomblé necessitando da atuação das mulheres do candomblé, por sua vez, as mães de santo, representadas por Mãe Judith, com seu falecimento na década de 1950, em determinado período como também pelas senhoras irmãs da irmandade de Nossa Senhora da Boa Morte.

Acredita-se que após o ano de 1976 houve um maior incentivo ao uso desta liberdade política e institucional que fortaleceu algumas iniciativas como o retorno da organização da festa de lemanjá, o Encontro das águas", a festa da Pechincha e a feijoada de Mãe Preta a partir do ano de 2014.

Confirmando assim a importância do papel das mulheres do candomblé na participação direta destas festividades e celebrações pelo fato do envolvimento do ou dos membros e adeptos terreiros de candomblé na organização das mesmas que vão desde a procura dos recursos a execução das tarefas.

\section{A procura de um entendimento conclusivo}

A atuação das mulheres do candomblé, em suas múltiplas atuações, esteve e está muito relacionada a história de Cachoeira desde a sua fundação como cidade em até os dias atuais por meio da promoção e valorização das tradições de matriz africana.

Este desempenho é marcado pelas sacerdotisas "mães de santo" e "ialorixás" na liderança de um terreiro de candomblé ou em uma irmandade feminina de cor como no caso da Boa Morte por intermédio de uma irmã.

A participação destas lideranças é fortemente marcada em 1860, período de institucionalização do candomblé e entre os anos de 1910 a 1930, com a perseguição política, midiática e policial a religião com destaque para a atuação de mãe Judith. 
O ano de 1976 será marcado pelo decreto estadual de 13 de janeiro que desobrigou a exigência de a licença para os terreiros solicitarem a delegacia de jogos e costumes para a realização dos rituais religiosos.

Em 1989 será um momento com destaque para a Irmandade da Boa Morte que em um conflito com a Igreja Católica irá afirmar a sua identidade afro-brasileira consolidando a sua importância com a visita de 400 turistas norte-americanos para as suas festividades no mês de agosto em Cachoeira.

O papel organizador, aglutinador e disseminador das mulheres do candomblé na mobilização da comunidade e no fortalecimento da sua função midiática demonstrando o prestígio que se dá no reconhecimento de uma prática religiosa historicamente perseguida, criminalizada e desqualificada.

A atuação conjunta destas mulheres do candomblé enfrentou e enfrenta uma ordem racista, excludente, capitalista e neoliberal por meio da promoção, inclusão e valorização da cultura negra e de matriz africana ao desenvolverem atividades aglutinadoras no interior de suas organizações como os terreiros e a irmandade.

Em uma conjuntura desfavorável historicamente marcada pela eugenia estas mulheres foram protagonistas na organização de instituições que enfrentaram e resolveram problemas atuando como agente de contestação, acolhimento e proteção de pessoas excluídas e a afirmação de uma identidade de matriz africana e afro-brasileira.

Assim houve o incentivo e o fortalecimento da liberdade individual, civil e política, sendo muitas vezes, necessário a ação conjunta para a compra da alforria de africanos escravizados e posteriormente no fortalecimento da atuação das lideranças das mulheres do candomblé como mães de santo e em outras funções.

Todas estas ações capitaneadas por estas mulheres do candomblé contribuíram e contribuem significativamente com o desenvolvimento do território de Cachoeira através da promoção da inclusão e autoestima dos (as) afro-brasileiros (as), do fluxo turístico e da circulação da economia local. 


\section{Referências Bibliográficas}

AGIER, Michel. As mães Pretas do ilê Aiyê: nota sobre o espaço mediano da cultura. In Revista Afro-Ásia, no 18, p. 189-203, Ceao (UFBA), Salvador, 1996.

A TARDE. Memória: Histórias de importantes sacerdotisas, ligadas a linhagem de Menininha, mostram o legado da fé dessas mulheres. As grandes senhoras da sabedoria. Salvador, $12 / 08 / 2007$.

BAHIA. Governo do Estado. Terreiros de Candomblé de Cachoeira e São Félix, organização Graça Lobo; coordenação Antonio Roberto Pellegrino Filho .- Salvador : Fundação Pedro Calmon : IPAC, 2015.

BAHIA. Governo do Estado. Secretaria de Promoção da Igualdade Racial - SEPROMI. Mapeamento dos Espaços de Religião de Matriz Africana do Recôncavo/ Sepromi. 1a Edição - Salvador; 2012.

BAHIA. Governo do Estado. Secretaria de Cultura. IPAC. Festa da Boa Morte. Salvador; Fundação Pedro Calmon; IPAC, 2011.

BAHIA. Governo do Estado. Secretaria de Cultura. IPAC. Festa da Boa Morte. Ed. revisada e ampliada Salvador; Fundação Pedro Calmon; IPAC, 2011.

CASTRO, Armando Alexandre Costa de. A Irmandade da Boa Morte: memória, intervenção e turistização da Festa em Cachoeira, Bahia. V 182 p. Dissertação (Mestrado) - Universidade Estadual de Santa Cruz/Universidade Federal da Bahia. Ilhéus (BA): UESC, 2005

CORRÊA, A.M. Espacialidades do sagrado: a disputa pelo sentido do ato de festejar da boa morte e a semiografia do território encarnador da prática cultural. In: SERPA, A., org. Espaços culturais: vivências, imaginações e representações [online]. pp. 161-179, Salvador: EDUFBA, 2008.

CORREIA, Sandro dos Santos. O território de Cachoeira-BA: O potencial do Patrimônio Cultural de Matriz Africana e as possibilidades para o Desenvolvimento Local do Recôncavo Baiano In CORREIA, S.C; DANTAS, A.L; SANTOS, E.M.P. (org.) Recôncavo Baiano: Trajetórias e Dinâmicas Territoriais, Salvador, Assembléia Legislativa, 2015.

JOAQUIM, Maria Salete. O papel da liderança religiosa feminina na construção da identidade negra - rio de Janeiro: Pallas; São Paulo: Educ, 2001.

LANDES, Ruth. A cidade das mulheres/ Ruth Landes; tradução de Maria Lúcia do Eirado Silva; revisão e notas de Édison Carneiro - 2ạ ed. ver. - Rio de Janeiro. Editora UFRJ, 2002.

LOPES, Nei. Enciclopédia Brasileira da Diáspora Africana. São Paulo, Selo Negro, 2004. 
MIRANDA, Anadir dos Reis. Mary Wollstonecraft e a reflexão sobre os limites do pensamento iluminista a respeito dos direitos das mulheres. Revista Vernáculo, n. 26, 20 sem./2010. http://revistas.ufpr.br/vernaculo/article/viewFile/20742/20618. Acesso em 10.07.2016.

NASCIMENTO, Luiz Cláudio Dias do. Bitedô: onde moram os nagôs: redes de sociabilidades africanas na formação do candomblé jêje-nagô no recôncavo baiano, Rio de Janeiro, CEAP. 2010.

PARÉS, Luis Nicolau. A formação do candomblé: história e ritual da nação jeje na Bahia. 2a ed. rev. Campinas, Editora da Unicamp, 2007.

PRANDI, Reginaldo. Mitologia dos orixás/ Reginaldo Prandi; ilustrações de Pedro Rafael. - São Paulo, Companhia das Letras, 2001.

ROSENDAHL, Zeny. Os caminhos da construção teórica: ratificando e exemplificando as relações entre espaço e religião. In ROSENDAHL, Zeny; CORRÊA, Roberto Lobato. Geografia Cultural: uma antologia (II). Rio de Janeiro: EdUERJ, 2013.

SANTOS, Nívea Alves dos. Entre ventos e tempestades: os caminhos de uma gaiaku de Oiá. Dissertação de Mestrado orientada por Luis Nicolau Parés do Programa Multidisciplinar de PósGraduação em Estudos Étnicos e Africanos da Faculdade de Filosofia e Ciências Humanas da Universidade Federal da Bahia, Salvador, 2013.

SANTOS, Edmar Ferreira. O poder dos candomblés: perseguição e resistência no Recôncavo da Bahia. Salvador, EDUFBA, 2009.

SEN, Amartya Kumar. Desenvolvimento como liberdade. Tradução: Laura Teixeira Motta. São Paulo: Companhia das Letras (Companhia de Bolso), 2015, 4a reimpressão.

SOUZA, Wiltércia Silva de. O sequestro das santas: a irmandade da Boa Morte e a igreja católica em Cachoeira, Bahia, 1989. Dissertação de Mestrado. Universidade do Estado da Bahia. Campus V. Departamento de Ciências Humanas. Santo Antônio de Jesus, Bahia, 2007.

VASCONCELOS, Pedro de Almeida. Cultura, Religião e Escravidão na Bahia (1549 - 1888). Espaço e Cultura, no 4. UERJ, Eduerj, Rio de Janeiro, Junho de 1997.

WALLERSTEIN, Immanuel. O universalismo europeu: a retórica do poder. Tradução: Beatriz Medina. São Paulo: Boitempo, 2007. 
Sandro dos Santos Correia: Professor Assistente do Campus V da UNEB (Universidade do Estado da Bahia), Mestre em Engenharia Ambiental Urbana pela Escola Politécnica da UFBA (Universidade Federal da Bahia), foi secretário municipal de reparação da cidade de Salvador em 2008 que lançou o selo da diversidade, doutorando em Planejamento Territorial e Desenvolvimento Social da UCSAL (Universidade Católica de Salvador) e Membro do Grupo de Pesquisa DSN (Desenvolvimento, Sociedade e Natureza) da UCSAL.

Artigo recebido para publicação em: Maio de 2017.

Artigo aprovado para publicação em: Junho de 2017. 